\title{
Paediatric palliative home care in areas of Germany with low population density and long distances: a questionnaire survey with general paediatricians
}

Kerstin Kremeike ${ }^{1,2^{*}}$, Nina Eulitz ${ }^{1}$, Saskia Jünger ${ }^{3}$, Annette Sander ${ }^{2}$, Max Geraedts ${ }^{4}$ and Dirk Reinhardt ${ }^{2}$

\begin{abstract}
Background: In 2007, the patient's right to specialised palliative home care became law in Germany. However, childhood palliative care in territorial states with low patient numbers and long distances requires adapted models to ensure an area-wide maintenance. Actually, general paediatricians are the basic care providers for children and adolescents. They also provide home care. The aim of this study was to improve the knowledge about general paediatrician's involvement in and contribution to palliative care in children.

Findings: To evaluate the current status of palliative home care provided by general paediatricians and their cooperation with other paediatric palliative care providers, a questionnaire survey was disseminated to general paediatricians in Lower Saxony, a German federal state with nearly eight million inhabitants and a predominantly rural infrastructure. Data analysis was descriptive.

One hundred forty one of 157 included general paediatricians completed the questionnaire (response rate: 89.8\%). A total of 792 children and adolescents suffering from life-limiting conditions were cared for by these general paediatricians in 2008. Severe cerebral palsy was the most prevalent diagnosis. Eighty-nine per cent of the general paediatricians stated that they had professional experience with paediatric palliative care.

Collaboration of general paediatricians and other palliative care providers was stated as not well developed. The support by a specialised team including 24-hour on-call duty and the intensification of educational programs were emphasised.
\end{abstract}

Conclusions: The current regional infrastructure of palliative home care in Lower Saxony can benefit from the establishment of a coordinated network of palliative home care providers.

Keywords: Children, Palliative care, Paediatrician's survey, Home care, Network, Prevalence

\section{Background}

Paediatric palliative care aims to improve the quality of life for children and adolescents suffering from lifelimiting conditions and their families [1]. Essential requirements for effective paediatric palliative care include a broad multi-disciplinary approach including available community resources. Families often prefer to

\footnotetext{
* Correspondence: kremeike.kerstin@mh-hannover.de

${ }^{1}$ Netzwerk für die Versorgung schwerkranker Kinder und Jugendlicher e.V, Carl-Neuberg-Straße 1, 30625 Hannover, Germany

${ }^{2}$ Department of Paediatric Haematology and Oncology, Hannover Medical

School, Carl-Neuberg-Straße 1, 30625 Hannover, Germany

Full list of author information is available at the end of the article
}

care for their ill child at home [2]. Therefore, the existence of local home care providers is crucial [3].

Generalists play an important role in palliative care in Germany as well as in other countries $[4,5]$. In the German health care system, general paediatricians provide medical home care for children and adolescents. Since they can make life-changing treatment decisions, optimal professional expertise, including the various aspects of palliative home care, is essential to providing appropriate support for patients and families [6,7].

General paediatricians working in private practice are supposed to be familiar with the basic principles of

\section{Biomed Central}


palliative care $[8,9]$; however, this may be hampered by marginal experience with palliative patients $[10,11]$. Heterogeneous life-limiting diseases and unpredictable clinical courses [12-14] are major causes of insecurity among general paediatricians when it comes to managing a palliative situation $[11,15,16]$.

Lower Saxony is a federal state in north-western Germany with nearly eight million inhabitants, a predominantly rural infrastructure, and about 470 paediatricians working in private practice. Data on the prevalence of life-limiting conditions in the region are missing.

To date, paediatric palliative home care in Germany is characterised by a shortage of financial resources and insufficient staff [17]. In Lower-Saxony, a regional tailored concept of a comprehensive specialist paediatric palliative home care has been implemented, as anchored in the German social legislation in April 2007.

The aim of the study was to evaluate involvement in and contribution of general paediatricians in paediatric palliative care and their cooperation with other paediatric palliative care providers. The latter can be seen as crucial for adequate paediatric palliative care - especially in rural areas with low patient numbers and long distances like Lower Saxony, where huge distances complicate effective paediatric palliative care [18].

\section{Findings \\ Methods}

The survey was conducted between May and December 2009. Data on patients' characteristics, management, and networking were asked going back to 2008. A standardised questionnaire was designed based on

- an established instrument used in North-Rhine Westphalia (NRW), another German federal state $[7,10]$;

- the classification of life-limiting conditions first described by the Association for Children with Life Threatening or Terminal Conditions and their Families (ACT) (see Table 1) [19,20]; and

- a review of the literature $[11,15,21,22]$.

The questionnaire developed by Juenger et al. in NRW was based on a qualitative exploration [10]. This instrument was adjusted for the purpose of our study by replacing a section on the role of the general paediatricians with questions on interdisciplinary professional networking and the transition from inpatient to outpatient care known as a particular challenge [23]. The modification was done to obtain more detailed information on the cooperation between general paediatricians and other paediatric palliative care providers, being a topic of special interest in areas with low patient numbers and long distances like Lower Saxony.
Table 1 Classification of life-limiting conditions according to the Association for Children with Life Threatening or Terminal Conditions and their Families (ACT) $[19,20]$

\begin{tabular}{|c|c|}
\hline Group 1 & $\begin{array}{l}\text { Conditions for which treatment with curative } \\
\text { intention is feasible but might fail, e.g., cancer or } \\
\text { irreversible organ failure. }\end{array}$ \\
\hline Group 2 & $\begin{array}{l}\text { Conditions for which there are long periods of } \\
\text { intensive treatment aimed at prolonging good-quality } \\
\text { life but for which premature death is anticipated, } \\
\text { e.g., cystic fibrosis, muscular dystrophy. }\end{array}$ \\
\hline Group 3 & $\begin{array}{l}\text { Progressive condition where treatment is exclusively } \\
\text { palliative from the time of diagnosis and may extend } \\
\text { over many years, e.g., metabolic disorders. }\end{array}$ \\
\hline Group 4 & $\begin{array}{l}\text { Conditions with severe disability, often neurological, } \\
\text { which although not progressive cause extreme } \\
\text { vulnerability to health complications and where } \\
\text { premature death is anticipated, e.g., severe cerebral } \\
\text { palsy, chromosomal disorders. }\end{array}$ \\
\hline
\end{tabular}

Furthermore, the original instrument was upgraded by introducing the ACT classification $[19,20]$ at the beginning of the questionnaire, assuming that paediatricians could have difficulties considering all life-limiting conditions as such. Beyond that, year dates were added to all questions concerning patients' characteristics, management, and networking to generate more detailed data.

The therewith-obtained questionnaire consisted of 25 questions addressing the following aspects:

- Previous experience with and exposure to situations requiring paediatric palliative care

- Interdisciplinary professional networking and the transition from inpatient to outpatient care

- Potential difficulties and incentives specifically associated with the involvement of general paediatricians in paediatric palliative care $[7,16,21]$

- Demographical data

The questionnaire used a homogeneous item-andresponse format (six-point Likert scales) to evaluate potential difficulties and incentives; free-text options were given to specify the prior experience in paediatric palliative care, the cooperation with other care providers, possible barriers and incentives, and - in a separately formulated closing question - to give the opportunity for suggestions and supplementary notes.

The generated questionnaire (see Additional file 1 for the final version) was pilot-tested with nine general paediatricians working in private practice. Resulting from the pilot test, a more detailed oral introduction of the ACT categories was given during the following survey. Ethical approval for the study was given by the Ethics Committee of the Medical School Hannover.

In Germany, all paediatricians working in private practice are required to participate in a regional quality circle in order to meet the demands of continuing medical 
education. Therefore, the investigators (KK and NE) visited all 11 regional paediatric quality circles in Lower Saxony, explained the research goal, distributed the questionnaires, collected them after completion and were available for questions or comments. Participants took an average of 20 minutes to complete the questionnaire.

Descriptive analyses were performed using the Statistic Package for Social Sciences (SPSS) 18.0.

\section{Results}

Sample

Out of 156 questionnaires distributed, 141 were completed. Sixteen paediatricians refused to answer the questionnaire for various reasons, resulting in a response rate of $89.8 \%$.

More than one-third $(53,37.6 \%)$ of the participants worked in a mainly rural environment, and $56.7 \%(80)$ worked in an urban area. A minority $(8,5.7 \%)$ did not specify the region they were working in.

The average age of the participants was 51 years (range 33 - 68 years), with $86(61.0 \%)$ of them being male. The paediatricians reported a median work experience of 11 years (range 1 to 31). The mean number of patient contacts was 1400 per quarter-year. More than half of the paediatricians $(82,58.2 \%)$ worked in their practice on their own, and 58 (41.1\%) worked in a group practice. The characteristics of the participating paediatricians and the reported patients are comparable to the total groups in Lower Saxony [24].

\section{Previous experience with and exposure to situations requiring paediatric palliative care}

Most of the participants (128/141, 90.8\%) stated that they have had experience with palliative care, and 87 (61.7\%) had taken care of children in the terminal phase of a life-limiting disease at home.

In 2008, the paediatricians were involved in the management of 792 children suffering from life-limiting conditions; $38(4.8 \%)$ of these children died in the same year. The majority of children suffered from a condition that could be classified as ACT group 4 [19,20] (Table 1); most of them were afflicted by severe cerebral palsy. Table 2 shows the distribution of the stated conditions according to ACT groups and the most frequent diagnosis. Compared to the results in NRW, the distribution of conditions between the ACT groups shows significant differences for the ACT groups 1,3 , and $4 .^{\text {a }}$

Patients were in the following age groups: 0 to 5 years, 287 (40.4\%); between 6 and 10 years, 221 (31.1\%); 11 to 18 years, $176(24.8 \%)$; and older than 18 years, $26(3.7 \%)$ (no data: 82, 8.4\%). Figure 1 illustrates the reported cases of life-limiting conditions by ACT group and age.

\section{Disposition to commit oneself to palliative medicine}

Asked if they would be disposed to engage (further) in palliative home care for children and adolescents, more than half $(74,52.5 \%)$ of the paediatricians said they would, while 66 (46.8\%) did not want to be involved.

\section{Interdisciplinary and trans-sectional professional networking}

Nearly all participants affirmed the existence of local specialist paediatric palliative care providers; 89 (63.1\%) of them reported 1 to 3 such providers, and 37 (26.2\%) named 4 or more. Mostly a local children's hospital was mentioned, followed by a paediatric home care nursing service, a psychotherapist, and a children's hospice. Limited knowledge was reported about paediatric home hospice services and parents' associations (Table 3).

Almost $90 \%$ of the participants collaborated with local specialist paediatric palliative care providers for the provision of care, more than three-quarters of them with a children's hospital, and two-thirds with a paediatric home care nursing service. The pattern of networking for joint patient care between general paediatricians and local specialist paediatric palliative care providers is listed in Table 3.

As reasons for initiating collaboration with other care providers, most paediatricians $(101,71.6 \%)$ mentioned psychosocial support for the patient and his family, which was most frequently provided by a paediatric home care nursing service. Further reasons for collaborating with

Table 2 Conditions stated by the paediatricians according to ACT groups and main diagnosis (2008)

\begin{tabular}{llll}
\hline & $\begin{array}{l}\text { Number of patients } \\
\text { (percentages of total) }\end{array}$ & Main diagnosis & $\begin{array}{l}\text { Number of patients } \\
\text { (percentages within the ACT Group) }\end{array}$ \\
\hline ACT group 1 & $151(19.1 \%)$ & Malignant diseases, Vitium Cordis & $80(53.0 \%), 51(33.8 \%)$ \\
ACT group 2 & $146(18.4 \%)$ & Cystic fibrosis, Duchenne muscular dystrophy & $91(62.3 \%), 51(33.8 \%)$ \\
ACT group 3 & $91(11.5 \%)$ & Metabolic disorders & $66(72.5 \%)$ \\
ACT group 4 & $358(45.2 \%)$ & Cerebral palsy, Chromosomal disorders & $209(57.7 \%), 73(20.4 \%)$ \\
Classification not possible & $46(5.8 \%)$ & Diverse syndromes & $20(30.3 \%)$ \\
Total & 792 & & \\
\hline
\end{tabular}




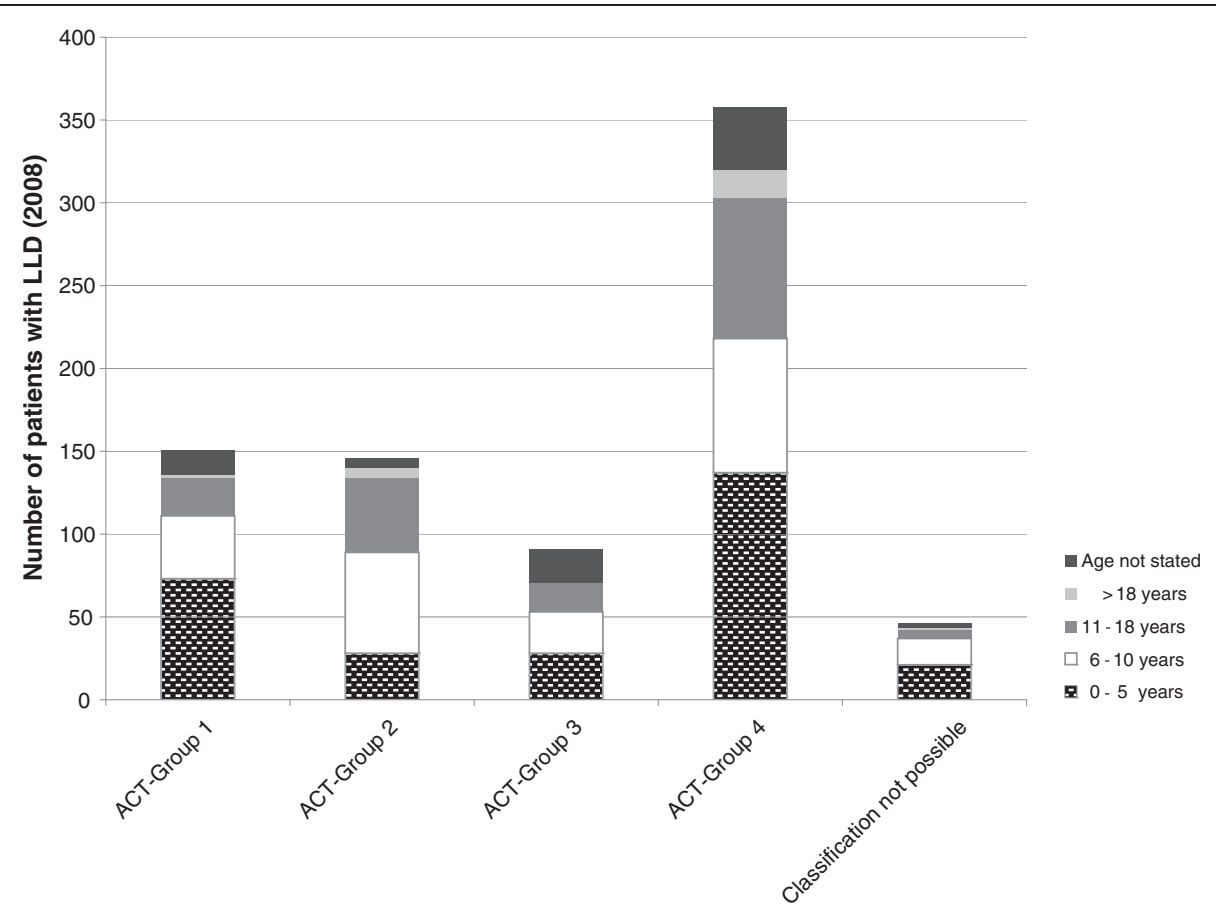

Figure 1 Children cared for by paediatricians in 2008. Illustration of reported cases of life-limiting diseases (LLD) by ACT group and age (Total: 792).

other local paediatric palliative care providers were supportive therapy such as intravenous medication and other invasive procedures, and the necessity of symptom and/or pain control (Table 3).

Fifty-two of the paediatricians (36.9\%) attested to problems during the transition from inpatient to outpatient paediatric palliative care. The main problem was poor information flow between the children's hospital, parents and general paediatricians (42, 29.8\%), especially regarding the preparation of patients and paediatricians for crisis intervention (15.6\%). Other documented factors included a lack of specialists $(17,12.1 \%)$.

\section{Barriers to and incentives for the implementation of palliative home care}

Palliative home care being a time-consuming occupation was perceived as a relevant challenge by 41 (29.6\%) of the participants. Thirty-six (25.5\%) of the general paediatricians complained about the lack of opportunities to exchange information with colleagues. Other perceived

Table 3 Reasons for joint patient care and participating disciplines (2008)

\begin{tabular}{|c|c|c|c|c|c|}
\hline \multirow{2}{*}{$\begin{array}{l}\text { Local specialist } \\
\text { paediatric } \\
\text { palliative care } \\
\text { providers }\end{array}$} & \multirow{2}{*}{$\begin{array}{l}\text { Paediatricians } \\
\text { aware } \\
\text { of this } \\
\text { service }\end{array}$} & \multirow{2}{*}{$\begin{array}{l}\text { Paediatricians } \\
\text { stating joint } \\
\text { patient } \\
\text { care with } \\
\text { this service }\end{array}$} & \multicolumn{3}{|c|}{$\begin{array}{l}\text { Reasons given for initiating a collaboration with other paediatric } \\
\text { palliative care providers }\end{array}$} \\
\hline & & & $\begin{array}{l}\text { Supportive therapy } \\
\text { (e.g., intravenous } \\
\text { medication) }\end{array}$ & $\begin{array}{l}\text { Symptom } \\
\text { control/pain } \\
\text { therapy }\end{array}$ & $\begin{array}{l}\text { Psychosocial } \\
\text { support }\end{array}$ \\
\hline Children's hospital & $129(91.5 \%)$ & $108(76.6 \%)$ & $72(51.5 \%)$ & $58(41.1 \%)$ & $44(29.1 \%)$ \\
\hline $\begin{array}{l}\text { Paediatric home care } \\
\text { nursing service }\end{array}$ & $110(78.0 \%)$ & $94(66.7 \%)$ & $41(29.1 \%)$ & $38(27.0 \%)$ & $51(36.2 \%)$ \\
\hline Psychotherapist & 71 (50.4\%) & $42(29.8 \%)$ & 0 & $1(0.7 \%)$ & $34(24.1 \%)$ \\
\hline Children's hospice & $62(44.0 \%)$ & $37(26.6 \%)$ & $10(7.1 \%)$ & 17 (12.1\%) & 28 (19.9\%) \\
\hline $\begin{array}{l}\text { Paediatric home } \\
\text { hospice service }\end{array}$ & $29(20.6 \%)$ & $11(7.8 \%)$ & 0 & 0 & $9(6.4 \%)$ \\
\hline Parents' association & 31 (22.0\%) & $8(5.7 \%)$ & $1(0.7 \%)$ & 0 & $8(5.7 \%)$ \\
\hline Total & 138 (97.9\%) & $126(89.4 \%)$ & $84(59.6 \%)$ & 78 (55.3\%) & $101(71.6 \%)$ \\
\hline
\end{tabular}


considerable hurdles are: discontinuity of care due to a temporary referral to a specialised service, such as specialist outpatient clinics $(22,15.6 \%)$; feeling overwhelmed by being solely responsible for a palliative situation $(19,13.5 \%)$; lack of adequate reimbursement $(18,12.8 \%)$; and the additional administrative burden 17 (12.1\%).

Most of the participants $(123,87.1 \%)$ considered the availability of local specialist services as a favourable facilitation for the implementation of paediatric palliative home care. Education in basic palliative medicine was favoured by 119 (84.4\%) and a sufficient information exchange with other care providers by 116 (82.3\%) of the general paediatricians. A $24 / 7$ on-call telephone service for paediatric palliative care was rated as an important incentive by 105 (74.5\%) participants.

Issues that would be addressed most frequently to the on-call service included pain control $(22,15.6 \%)$ and medication $(13,9.2 \%)$.

\section{Discussion}

In this study, the current status of palliative home care provided by general paediatricians in a territorial area has been analysed. The results provide relevant information on the paediatricians' needs and concerns. The findings also highlight areas of care provision that need further improvement. Therefore, the data contribute to the evidence on needs in paediatric palliative care, in particular for areas with low patient numbers and long distances.

\section{Experience with paediatric palliative care}

Most general paediatricians have had experience with palliative care situations in their professional practice. These findings are different from the results evaluated in NRW, which reported that less than half of the participants had such experiences [10]. This can be explained by the fact that the original instrument used in NRW was upgraded in this study: in addition to providing the WHO-definition of palliative care [25], in the questionnaire used in this study the ACT classification was introduced. This helped the participating paediatricians to correctly identify and classify their palliative care experience and is also the reason for a tenfold higher average number of patients per participant in Lower Saxony.

When extrapolating the number of patients reported by the paediatricians in this study to the population of Lower Saxony, a prevalence of about 2500 children can be assumed. This is in line with the data reported in international studies, assuming a prevalence of lifelimiting conditions of $0.1 \%$ to $0.15 \%$ in children and adolescents $[13,18,26]$. Due to the lack of information systems to accurately identify and register children with life-limiting conditions, the latter is based on the incidence of death rather than diagnosis, which might have an adverse effect on comparability. Although the generated data can only serve as an approximate value, this study generated the first data on the prevalence of life-limiting conditions in Lower Saxony, including a classification of age and disease groups. The information on the eligible population is essential for an effective advancement of paediatric palliative care [27].

The majority of children reported by the paediatricians in Lower Saxony suffered from a condition classified as ACT group 4 (45.2\%), mainly severe cerebral palsy. In contrast, the bigger proportion of children reported by the participants in NRW suffered from a condition of ACT group 1 (43.8\%), nearly all of them related to malignant diseases [10]. These significant differences indicate that it seems easier for paediatricians to recognise the need for palliative care when children are in the terminal phase of malignant diseases rather than suffering from cerebral palsy, chromosomal disorders, cystic fibrosis, or muscular dystrophy [28]. Our results suggest that the validity and reliability of data can be enhanced by choosing a question format that provides information about the possible range of life-limiting conditions, including non-malignant diseases.

These observations reflect the general debate on palliative care for children suffering from illnesses other than malignancies, which remains controversial [29]. Our results are in line with recent studies on palliative care for adults, finding that most generalists defined palliative care narrowly in terms of the very end of life and typically within the context of cancer [5], and that palliative care needs of non-cancer patients are often neglected [4]. But life-limiting conditions as per ACT groups 2 to 4 define the majority of paediatric patients in a palliative situation [30]; they are in many cases diagnosed at birth or early in life, and the courses of these diseases are highly unpredictable, most often emerging within the context of a diverse set of complex chronic conditions [31].

For all (potentially) life-limiting conditions the relationship between cure and palliation should not be considered as mutually exclusive, because a neglect of treatment options with palliative intentions can cause unmet needs of patients and families [32]. The more secure the attitude of general paediatricians towards this morally and medically challenging topic, the better the quality of the individually provided health care will be. The lack of understanding of palliative care amongst generalists is seen as a barrier to good palliative care provision for adults [5]. Our findings suggest that the general paediatricians' expertise on the various aspects of paediatric palliative care needs expansion to assure appropriate support for paediatric patients and families, especially when dealing with diseases other than cancer. 
The perception of paediatric palliative care as a philosophy that is integral to the paediatrician's practice could be achieved by the assistance of paediatric palliative care specialists and with professional exchange. Therefore, the best practice in specialist support is described as ranging from on-off consultation to full referral with the primary care team usually determining the need of support [33]. In areas with a predominantly rural infrastructure the assistance of palliative care specialists can best be realised by developing a systematic mechanism for sharing resources and providing consultation [34].

\section{Interdisciplinary and trans-sectoral professional networking}

Psychosocial support being the most striking reason for initiating collaboration with other care providers was also evaluated for general practitioners in palliative care for adults [35].

Within the paediatricians' awareness of the existence of other paediatric palliative service providers, paediatric hospice home services and parents' associations were clearly underrepresented when compared to children's hospitals or home care nursing services.

Communication and cooperation with medical staff seemed more obvious to paediatricians than with hospice services or parents' groups.

The detected lack of recognition of hospice services could also be a result of the paediatricians' unwillingness to accept the incurable condition of the child [21] and also of the fear of the word "hospice" as a generally understood synonym for "taking away hope" [36].

Temel et al. recently provided evidence that palliative care significantly improves the quality of life, mood, and life expectancy of adult cancer patients [37]. Even if this has to be verified for paediatric patients, it might be assumed that paediatric palliative care will enhance the situation of children and adolescents suffering from lifelimiting conditions. This potential benefit of paediatric palliative care has to be accessible for all children suffering from life-limiting conditions.

The mission of palliative care teams to meet the physical, psychological, emotional, spiritual, and social needs can best be accomplished by multi-professional cooperation [1]. The lack of familiarity with the availability and suitability of hospice services and parents' groups is an important barrier for their involvement when potentially appropriate [22]. To assure a good communication flow, central coordination achieved by the appointment of a primary professional in charge is recommended [38]. Based on these previous findings, the results of our study underline that adequate collaboration and specialised education of care providers are necessary to optimise the multi-professional cooperation in paediatric palliative care.
Concerning the transition from inpatient to outpatient paediatric palliative care, the information flow and communication, especially between children's hospital staff and both general paediatricians in private practices and parents, need improvement, because high-quality paediatric palliative care also depends on trans-sectoral linkages [23,39]. Hospital-based palliative care consultation services seem to be very appropriate in this regard, since they can provide support to the paediatrician while strengthening the relationships between the hospital staff and community service providers [11].

\section{Barriers to and incentives for the implementation of palliative home care}

In line with previous studies [7,16,21], time demand and lack of exchange in a team are the most prominent difficulties providing palliative home care in Lower Saxony.

The known lack of clearly defined legal and financial regulations is a significant obstacle for general paediatricians in the home care setting [7]; therefore, a clear legal regulation of general palliative home care is needed. This demand was already expressed in other countries [38]. Since April 2007, German social legislation has provided the individual the right to specialist palliative home care for all people with statutory health insurance. General palliative home care, as provided by general paediatricians, is not regulated yet and certainly needs advancement [40].

Besides the availability of a specialist paediatric care consultant team, education in basic palliative competence in this study was requested most for the implementation of paediatric palliative home care. In this regard, a small expenditure of time can already produce appreciable results in reassuring paediatric residents [41] and can be tailored to particular regional needs [42].

A noteworthy number of participants used the freetext option to express a need for support in pain therapy. The physicians' uncertainty in this regard has already been described before [15]. Many children experiencing life-limiting conditions suffer from pain at the end of their life [43], and pain relief is often insufficient $[13,44,45]$. Optimal pain control might therefore be mainly provided by specialists such as anaesthesiologists with special training in pain control, since general paediatricians often lack sufficient experience in this field.

The provision of palliative home care for adults is a special challenge within a predominantly rural infrastructure $[46,47]$. Because of the lower case numbers, it is even more difficult to offer a comprehensive specialist palliative home care for children and adolescents in areas with low population density and long distances; this can be met with the integration of existing structures, the bundling of competences, and good 
networking. Therefore, the cooperation of specialists and general paediatricians is crucial.

As for the general limitations of this study, collecting data for organisational reasons took place over a time period of ten months. Within this period, palliative care in Germany developed considerably, which might have partly affected the interpretation of our findings.

The paediatricians completed the questionnaire on an evening session of a quality circle, which probably had a negative impact on completeness and correctness, especially respective to the details on their patients.

\section{Conclusions}

Our findings suggest that cooperation between palliative care providers and paediatricians could be improved. Good information flow and coordination are key issues in this regard.

\section{Availability of supporting data}

The used questionnaire is available as Additional file 1 with the manuscript. For further questions, please contact the authors.

\section{Endnote}

Analysis of variance (ANOVA), level of significance: 0,05 .

\section{Additional file}

Additional file 1: Questionnaire on Paediatric Palliative Home Care by General Paediatricians in their own practice.

\section{Competing interests}

The authors declare that they have no competing interests.

\section{Authors' contribution}

KK participated in the conception, design, analysis, interpretation, and drafting of the manuscript. NE participated in the conception, design, analysis, interpretation, and revision of the manuscript. SJ participated in the conception, design, analysis, interpretation, and revision of the manuscript. AS participated in the conception, design, analysis, interpretation, and revision of the manuscript. MG participated in the conception, design analysis, interpretation, and revision of the manuscript. DR participated in the conception, design, analysis, interpretation, and revision of the manuscript. All authors read and approved the final manuscript.

\section{Acknowledgments}

We would like to thank Dr. Tilman Kaethner, the contact person of general paediatricians in Lower Saxony, and the participants of the quality circles for their cooperation.

\section{Author details}

${ }^{1}$ Netzwerk für die Versorgung schwerkranker Kinder und Jugendlicher e.V, Carl-Neuberg-Straße 1, 30625 Hannover, Germany. ${ }^{2}$ Department of Paediatric Haematology and Oncology, Hannover Medical School, Carl-Neuberg-Straße 1, 30625 Hannover, Germany. ${ }^{3}$ Department of Palliative Medicine, University Hospital of Bonn, Sigmund-Freud-Str. 25, 53127 Bonn, Germany. ${ }^{4}$ Institute for Health Systems Research, Witten/Herdecke University,

Alfred-Herrhausen-Straße 50, 58448 Witten, Germany.
Received: 16 March 2012 Accepted: 1 September 2012

Published: 11 September 2012

\section{References}

1. Craig F, Abu-Saad Huijer H, Benini F, Kuttner L, Wood C, Feraris PC, et al: IMPaCCT: standards of paediatric palliative care. European Journal of Palliative Care 2007, 14(3):109-114.

2. Vickers J, Thompson A, Collins GS, Childs M, Hain R: Place and provision of palliative care for children with progressive cancer: a study by the Paediatric Oncology Nurses' Forum/United Kingdom Children's Cancer Study Group Palliative Care Working Group. J Clin Oncol 2007, 25(28):4472-4476.

3. Goldman A, Beardsmore S, Hunt J: Palliative care for children with cancerhome, hospital, or hospice? Arch Dis Child 1990, 65(6):641-643.

4. Brueckner T, Schumacher M, Schneider N: Palliative care for older people exploring the views of doctors and nurses from different fields in Germany. BMC Palliat Care 2009, 8:7.

5. Gott M, Seymour J, Ingleton C, Gardiner C, Bellamy G: 'That's part of everybody's job': the perspectives of health care staff in England and New Zealand on the meaning and remit of palliative care. Palliat Med 2012, 26(3):232-241.

6. Knapp CA, Madden VL, Curtis CM, Sloyer PJ, Huang IC, Thompson LA, et al: Partners in care: together for kids: Florida's model of pediatric palliative care. J Palliat Med 2008, 11(9):1212-1220.

7. Jünger $S$, Pastrana T, Pestinger M, Kern M, Zernikow B, Radbruch L: Barriers and needs in paediatric palliative home care in Germany: a qualitative interview study with professional experts. BMC Palliat Care 2010, 9:10.

8. American Academy of Pediatrics: Committee on Bioethics and Committee on Hospital Care. Palliative care for children. Pediatrics 2000 106(2 Pt 1):351-357.

9. Work group of the National Hospice and Palliative Care Organization: A call for change: Recommendations to improve the care of children living with life-threatening conditions. 2001, Available at http://www.nhpco.org/ files/public/ ChiPPSCallforChange.pdf. Accessed 12/15, 2011.

10. Jünger $S$, Vedder $A E$, Milde $S$, Fischbach $T$, Zernikow $B$, Radbruch $L$ : Paediatric palliative home care by general paediatricians: a multimethod study on perceived barriers and incentives. BMC Palliat Care 2010, 9:11.

11. Sheetz MJ, Bowman MA: Pediatric palliative care: an assessment of physicians' confidence in skills, desire for training, and willingness to refer for end-of-life care. Am J Hosp Palliat Care 2008, 25(2):100-105. Apr-May.

12. Goldman $A: A B C$ of palliative care. Special problems of children. BMJ 1998, 316(7124):49-52.

13. Lenton S, Stallard P, Lewis M, Mastroyannopoulou K: Prevalence and morbidity associated with non-malignant, life-threatening conditions in childhood. Child Care Health Dev 2001, 27(5):389-398.

14. Hynson JL, Gillis J, Collins JJ, Irving H, Trethewie SJ: The dying child: how is care different? Med J Aust 2003, 179(6 Suppl):S20-S22.

15. Contro NA, Larson J, Scofield S, Sourkes B, Cohen HJ: Hospital staff and family perspectives regarding quality of pediatric palliative care. Pediatrics 2004, 114(5):1248-1252.

16. De Graves S, Aranda S: When a child cannot be cured - reflections of health professionals. Eur J Cancer Care (Engl) 2005, 14(2):132-140.

17. Friedrichsdorf SJ, Menke A, Brun S, Wamsler C, Zernikow B: Status Quo of Palliative Care in Pediatric Oncology - A Nationwide Survey in Germany. J Pain Symptom Manage 2005, 29(2):156-164

18. Department of Health and Children and The Irish Hospice Foundation: $A$ Palliative Care Needs Assessment for Children. Dublin: Stationery Office; 2005.

19. Association for Children with Life Threatening or Terminal Conditions and their Families and Royal College of Paediatrics and Child Health: A guide to the development of children's palliative care services. Bristol, London: ACT, RCPCH; 1997.

20. Hynson JL: The child's journey: Transition from health to ill-health. In Oxford Textbook of Palliative Care for children. Edited by Goldman A, Hain R, Liben S. New York: Oxford University Press; 2006:14-27.

21. Davies B, Sehring SA, Partridge JC, Cooper BA, Hughes A, Philp JC, et al: Barriers to palliative care for children: perceptions of pediatric health care providers. Pediatrics 2008, 121(2):282-288. 
22. Feeg VD, Elebiary H: Exploratory study on end-of-life issues: barriers to palliative care and advance directives. Am J Hosp Palliat Care 2005, 22(2):119-124

23. Carroll JM, Santucci G, Kang TI, Feudtner C: Partners in pediatric palliative care: a program to enhance collaboration between hospital and community palliative care services. Am J Hosp Palliat Care 2007, 24(3):191-195. Jun-Jul.

24. Dokumentations-, Archivierungs-, Recherche- und Informationssystem der Kassenärztlichen Bundesvereinigung und der Kassenärztlichen Vereinigungen. Available at: http://daris.kbv.de/daris.asp. Accessed 12/15, 2011.

25. Sepúlveda C, Marlin A, Yoshida T, Ullrich A: Palliative Care: the World Health Organization's global perspective. J Pain Symptom Manage 2002, 24(2):91-96.

26. Feudtner C, Hays RM, Haynes G, Geyer JR, Neff JM, Koepsell TD: Deaths attributed to pediatric complex chronic conditions: national trends and implications for supportive care services. Pediatrics 2001, 107(6):E99.

27. Bona K, Bates J, Wolfe J: Massachusetts' pediatric palliative care network: successful implementation of a novel state-funded pediatric palliative care program. J Palliat Med 2011, 14(11):1217-1223.

28. Knapp C, Thompson L, Madden V, Shenkman E: Paediatricians' perceptions on referrals to paediatric palliative care. Palliat Med 2009, 23(5):418-424.

29. McCulloch R, Comac M, Craig F: Paediatric palliative care: coming of age in oncology? Eur J Cancer 2008, 44(8):1139-1145.

30. Lenton S, Goldman A, Eaton N, Southall D: Development and epidemiology. In Oxford Textbook of Palliative Care for children. Edited by Goldman A, Hain R, Liben S. New York: Oxford University Press; 2006:3-13.

31. Feudtner C, Kang TI, Hexem KR, Friedrichsdorf SJ, Osenga K, Siden H, et al: Pediatric palliative care patients: a prospective multicenter cohort study. Pediatrics 2011, 127(6):1094-1101.

32. Hutchinson F, King N, Hain RD: Terminal care in paediatrics: where we are now. Postgrad Med J 2003, 79(936):566-568.

33. Schneider N, Mitchell GK, Murray SA: Palliative care in urgent need of recognition and development in general practice: the example of Germany. BMC Fam Pract 2010, 11:66.

34. Schrader SL, Nelson ML, Eidsness LM: Palliative care teams on the prairie: composition, perceived challenges \& opportunities. S D Med 2007, 60 (4):147-149. Apr;60.

35. Borgsteede SD, Deliens L, van der Wal G, Francke AL, Stalman WA, van Eijk JT: Interdisciplinary cooperation of GPs in palliative care at home: a nationwide survey in The Netherlands. Scand J Prim Health Care 2007, 25(4):226-231.

36. Toce $\mathrm{S}$, Collins MA: The FOOTPRINTS model of pediatric palliative care. J Palliat Med 2003, 6(6):989-1000.

37. Temel JS, Greer JA, Muzikansky A, Gallagher ER, Admane S, Jackson VA, et al: Early palliative care for patients with metastatic non-small-cell lung cancer. N Engl J Med 2010, 363(8):733-742.

38. Craft A, Killen S: Palliative Care Services for Children and Young People in England. An Independent Review for the Secretary of State for Health. 2007

39. Monterosso L, Kristjanson L, Phillips MB: The supportive and palliative care needs of Australian families of children who die from cancer. Palliat Med 2009, 23(6):526-536.

40. Schneider N, Engeser P, Behmann M, Kuhne F, Wiese B: Specialized outpatient palliative care. The expectations of general practitioners. Schmerz 2011, 25(2):168-173. Apr.

41. Schiffman JD, Chamberlain L, Palmer L, Contro N, Sourkes B, Sectish TC: Introduction of a pediatric palliative care curriculum for pediatric residents. J Palliat Med 2008, 11(2):164-170.

42. Kelley ML, Habjan S, Aegard J: Building capacity to provide palliative care in rural and remote communities: does education make a difference? J Palliat Care 2004, 20(4):308-315.

43. Drake R, Frost J, Collins JJ: The symptoms of dying children. J Pain Symptom Manage 2003, 26(1):594-603.

44. Zernikow B, Dietz B: Schmerzerkennung, -messung und -therapie bei Kindern mit kognitiver und körperlicher Behinderung. Neuropädiatrie in Klinik und Praxis 2003, 2:12-17.
45. Howard RF: Current status of pain management in children. JAMA 2003, 290(18):2464-2469.

46. Cassel JB, Webb-Wright J, Holmes J, Lyckholm L, Smith TJ: Clinical and financial impact of a palliative care program at a small rural hospital. J Palliat Med 2010, 13(11):1339-1343.

47. Masso $\mathrm{M}$, Owen $\mathrm{A}$ : Linkage, coordination and integration: evidence from rural palliative care. Aust J Rural Health 2009, 17(5):263-267.

doi:10.1186/1756-0500-5-498

Cite this article as: Kremeike et al:: Paediatric palliative home care in areas of Germany with low population density and long distances: a questionnaire survey with general paediatricians. BMC Research Notes 2012 5:498.

\section{Submit your next manuscript to BioMed Central and take full advantage of:}

- Convenient online submission

- Thorough peer review

- No space constraints or color figure charges

- Immediate publication on acceptance

- Inclusion in PubMed, CAS, Scopus and Google Scholar

- Research which is freely available for redistribution 